\title{
Experimental study on static thrust characteristics of Master Airscrew E9x6 propeller with duct
}

\author{
Nguyen Ho Nghia and Ngo Khanh Hieu
}

\begin{abstract}
Previous studies at HCMUT have been carried out on free propellers in static condition for Unmanned Aerial Vehicle (UAV), not much data exists for ducted propellers. According to theory, the ducted propeller has some better characteristics than than the free propeller. The paper presents an experimental design, based on load-cell deformation, for the small ducted propeller. The experimental model will be carried out for the Master Airscrew E9x6 propeller in the case with duct and without duct, in the static condition. The results obtained will be compared with the manufacturer's results (conducted by the University of Illinois, without duct, in static condition), and compared to the numerical simulation results. From there, choose the kind of propeller that match the design of the UAV.
\end{abstract}

Index Terms - thrust measurement system, ducted propeller, Master Airscrew E9×6 propeller

\section{INTRODUCTION}

$\mathrm{P}$ ropeller performance at low Reynolds numbers has become increasingly important in the design and performance prediction of unmanned air vehicles (UAVs). While propeller performance for full-scale airplanes has been well documented since the pioneering days of aviation, data on propellers at low Reynolds numbers has been scarce.

Manuscript Received on March 15 $5^{\text {th }}$ 2017, Manuscript Revised on November 01 ${ }^{\text {st }}, 2017$.

The authors sincerely thank the Mechanical Engineering Laboratory, Faculty Applied Science, Ho Chi Minh City University of Technology, VNU-HCM, for giving the equipment to serve this research.

Nguyen Ho Nghia, Department of Aerospace Engineering, Ho Chi Minh City University of Technology, VNU-HCM (email: nhnghia208@gmail.com)

Ngo Khanh Hieu, Department of Aerospace Engineering, Ho Chi Minh City University of Technology, VNU-HCM (email: ngokhanhhieu@hcmut.edu.vn)
The Small Unmanned Aerial Vehicle (SUAV) now has two popular types: the fixed-wing aircraft (fixed-wing SUAV) and a type with multiple propellers (multi rotors SUAV). Advantages of the "fixed-wing SUAV" that allows a rapid deployment to the location of a task with greater stability and better control ability, time tasks can be up to 2 hours. However, this unmanned aircraft requires a space large enough, there is a certain flatness for the take-off and landing. Meanwhile, the type "multi rotors SUAV" does not require the takeoff and landing space which is a large area, it can easily take off and land on a variety of different terrains; in return it has many limitations on stability and control (because the main dependence on circuit boards and control algorithm of the system), and mission time (usually no more than 1 hour).

Due to the rapid-deployment features, compact, easy to carry, the unmanned aerial vehicle used more multiple propellers is currently popular in civilian applications for the purpose of observing in the near range. To increase the operational efficiency of the air propeller as well as the safety use, the propeller was developed into propeller in nozzle (see Fig. 1). A ducted propeller consists of a combination of an annular airfoil and an impeller, acting as a propulsion unit.

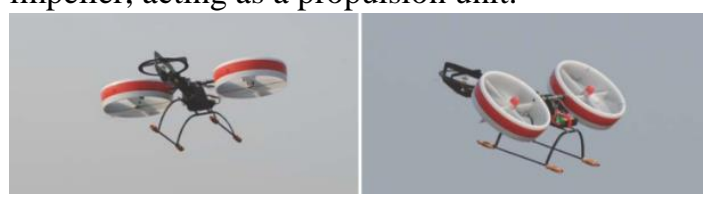

Fig. 1. An UAV used 3 ducted propellers [1]

Compared to the unducted propeller, ducted propeller shows a higher performance. With the same power generating, the propeller in nozzle will have lower requirement of capacity. This development will help greatly to improve the flight 
time of the unmanned aircraft with the propeller in nozzle.

Previous studies in the Department of Aerospace Engineering, Ho Chi Minh City University of Technology (HCMUT) - Vietnam National University - Ho Chi Minh City were successful with a thrust measurement system for unducted electric propeller [2] (see Fig. 2) used for many small UAVs.

In this paper, we will present how to set up a thrust measurement system for ducted propeller to evaluate the effect of the duct on the thrust characteristics of electric propellers. The tests were performed in static condition. However, this testing system could be integrated in the test section of wind tunnel for the experiments in dynamic conditions.

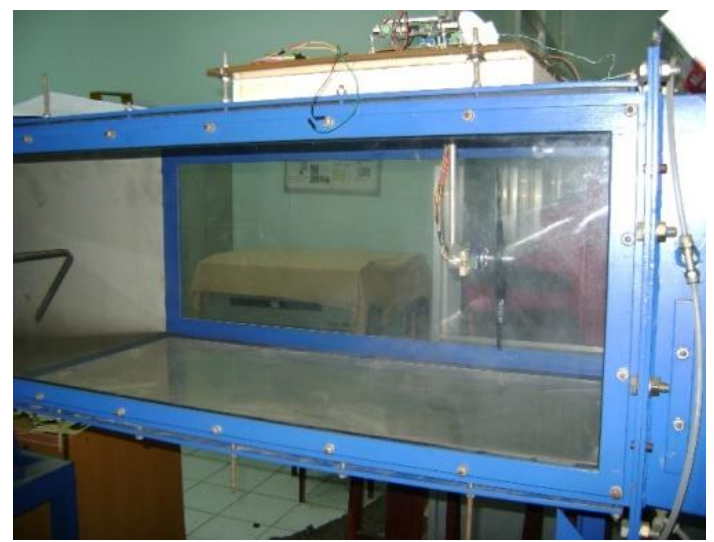

Fig. 2. Experimental performance characteristics of the free propeller at HCMUT [2]

The electric propeller used for experiments is a Master Airscrew E9 $\times 6$ propeller, named MA $99 \times 6$ (see Fig. 3).

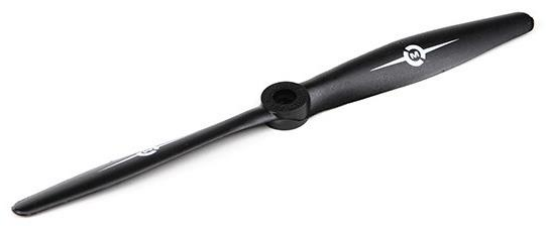

Fig. 3. Master Airscrew E9 $\times 6$ propeller

\section{EXPERIMENTAL PRINCIPLES \& EQUIPMENTS}

\subsection{Principles}

Principle diagram of a thrust measurement system are as follows:

When the system is powered, the speed of the propeller is adjusted by the electronic speed controller. The thrust generated by the propeller is captured by strain-gages in form of an activedummy full wheatstoe bridge. Due to the characteristics of the propeller operating in static, stable conditions and reaching established status rapidly under its revolution, a frequency sampling of $10 \mathrm{~Hz}$ with a sample time of 10 minutes is sufficient for this propeller's static thrust characteristics.

The electrical parameters during tests such as: supplied voltage, electric current, revolution of electric motor... were logged by the V4 E-Logger of Eagle Tree Systems [2].

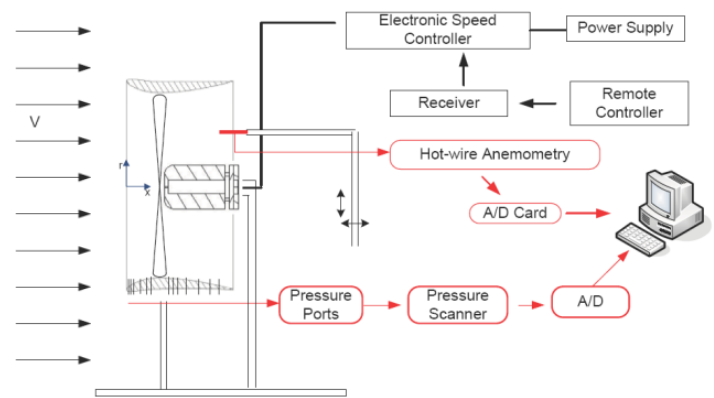

Fig. 4. Principles of the thrust testing system [2]

\subsection{Error of the thrust measurement system}

The load cell type used to obtain the thrust data is an active dummy full wheatstone bridge. According to [3], a strain-gauge with a Poisson coefficient of 0.286 , the $\mathrm{K}_{\mathrm{t}}$ of $-0.2 \%$ would have a measurement error due to manufacture of $0.041 \%$, resulting an overall error of strain-gauge of $0.141 \%$. However, with the same Poisson coefficient, if the value of $\mathrm{K}_{\mathrm{t}}$ is $-3.0 \%$, the measurement error generated by manufacture would be $0.654 \%$, resulting an overall error of strain-gauge of $0.754 \%$. So for the design of a lowcost testing system, the selected load-cell (see Fig. 5) having a transverse sensitivity coefficient $\left(K_{t}\right)$ of $-3.0 \%$. Hence, the error circuit of the thrust measurement system is $3.0 \%(=4 \times 0.754 \%)$.

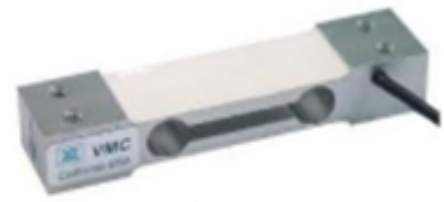

Fig. 5. Load cell VLC A-314 [4]

The choice of data acquisition device influences the uncertainty of the measurement result captured by the force balance. Most of data acquisition devices are built on industry standards, so they incorporate the noise filters. However, the reliability and the accuracy of these devices are quite different. For example, a low-cost data acquisition device like Jadever JWI-3100 of Taiwan has a tolerance of $\pm 3.0 \%$ (see Fig. 6); a 
high-cost device like NI myDAQ of National Instrument has an error of $\pm 0.5 \%$.
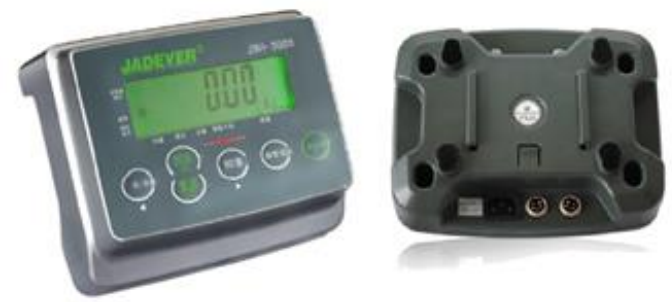

Fig. 6. Jadever JWI-3000 [5]

With low-cost acquisition device such as Jadever JWI-3000, the overall error of thrust measurement system presented in this paper is about $\pm 6 \%$.

\subsection{Calibration}

The calibration process is as follows:

- Thread the wires to the motor shaft, making sure the wires are horizontal. Then through the pulley to be able to hang the balance.

- Use standard weights weighing in the range of force that the engine can generate: $10 \mathrm{~g}, 20 \mathrm{~g}$, $30 \mathrm{~g} . .$. in turn to set the balance.

- Record the value displayed on the loadcell for each weight, then output the calibration curve of the loadcell.

- Use the calibration curve to serve the experimental process.

\subsection{Experimental process}

Experimental process of propeller's thrust characteristics in static condition is carried out in the following steps:

a. Installation of the system by the thrust of the pedal to the pedestal. Check the installation to ensure that the measuring system is fixed to the mounting base.

b. Connects the load-cell resistor to the Jadever JWI-3000. Check the display of the "load-cell" signal on the Jadever JWI-3000.

c. Connect the Jadever JWI-3000 to your computer via the RS-232 interface. Check the display and output of the Jadever JWI-3000 to the computer at a sampling frequency of $10 \mathrm{~Hz}$.

d. Wire connection of the brushless electric motor to the ESC speed regulator, check the direction of rotation to ensure correct rotation required during the experiment.

e. Connect the ESC accelerator signal to the V4 E-Logger, and connect the V4 E-Logger to the computer via a device-powered cable. Check the output from the V4 E-Logger displayed on the computer.

f. Power supply for electric motors.

g. Activate the Jadever JWI-3000 in processing mode and output the results to the computer.

h. Activate the V4 E-Logger in processing mode and output the results to the computer.

i. Controlling the rotation of the electric motor to a desired value (the rotation setting time for the brushless electric motor in this case is quite short, seconds to tens of seconds).

j. Record the empirical value for the rotation determined from step (j) with a minimum duration of 10 minutes.

k. Put the rotation of the electric motor to zero. And wait about 30 to 60 seconds for the system to return to its pre-experimental state.

1. Stop the processing and export of the results to the computer of the Jadever JWI-3000, which stores the previously recorded data into a data file for post-test analysis.

$\mathrm{m}$. Stop the processing and output to the computer of the V4 E-logger, store the previously recorded data as a data file for post-test analysis.

n. Proceeding from (h) to (n) with another set of electric motors.

o. End the experiment by disconnecting the power supply to the motor, disconnecting the connections to the computer and with the measuring system, remove the force gauge from the pedestal.

\section{DESIGN Of DuCT}

There are two main nozzle types: acceleration and deceleration, the difference between these two types is the velocity distribution in inlet/outlet of the nozzle. For the first one, the velocity of the input stream is smaller than the output and the other is opposite (see Fig. 7). 


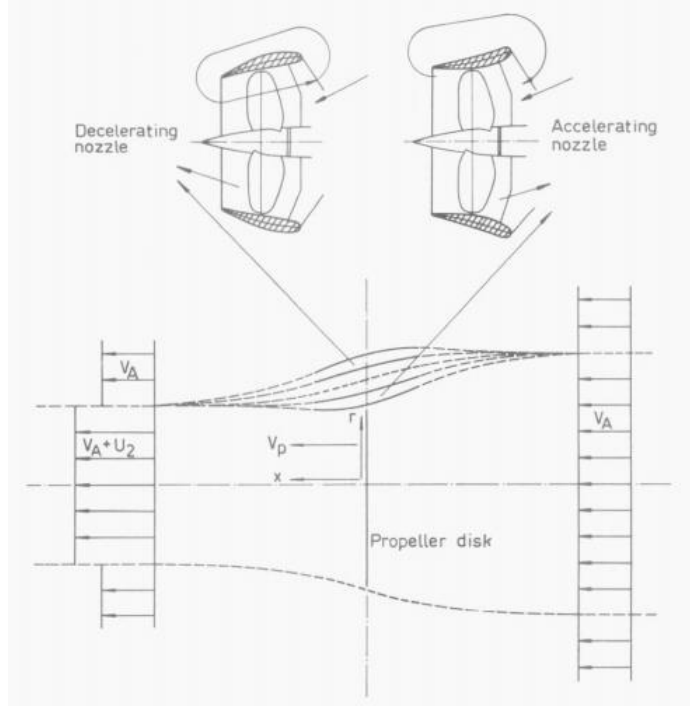

Fig. 7. General form of streamlines enforced by different nozzle types [6]

The main geometrical characteristics of a duct have shown in Fig. 8, where:

- L: duct's length

- C: the gap between the wingtip and the trailing edge.

- $t$ : the maximum thickness of the duct.

- $C_{x}=A x / A$ : the ratio between the inlet area and cross-sectional area of duct.

- $C_{y}=A y / A$ : the ratio between the outlet area and cross-sectional area of duct.

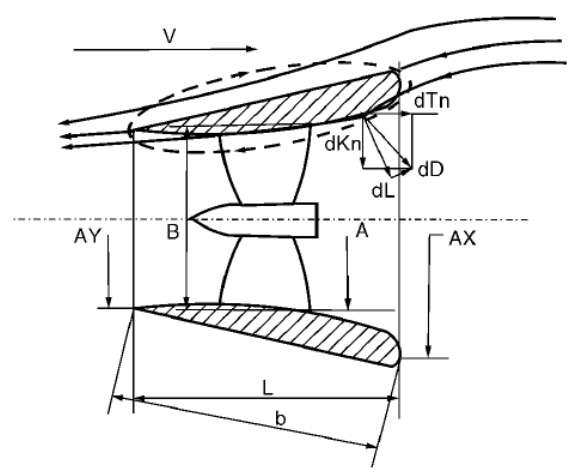

Fig. 8. Profile of nozzle [6]

Based on the standard of the research center of Wageningen in Netherlands [6], the current manufacturing technology at HCMUT, the duct is designed by Wageningen 19A standard and manufactured by 3D printing method.

Fig. 9 and table 1 show the geometry of duct and its geometrical parameters.
TABLE 1

GEOMETRICAL PARAMETERS OF DUCT

\begin{tabular}{|c|c|}
\hline Quantity & Value \\
\hline Inner diameter $\left(D_{\text {in }}\right)$ & $450 \mathrm{~mm}$ \\
\hline Outer diameter $\left(\mathrm{D}_{\text {out }}\right)$ & $300 \mathrm{~mm}$ \\
\hline Duct's length & $160 \mathrm{~mm}$ \\
\hline $\begin{array}{l}\text { Location of the propeller (from the front } \\
\text { edge of the nozzle) }\end{array}$ & $185 \mathrm{~mm}$ \\
\hline $\begin{array}{l}\text { Distance between the wingtip and the edge } \\
\text { of the nozzle }\end{array}$ & $1 \mathrm{~mm}$ \\
\hline
\end{tabular}
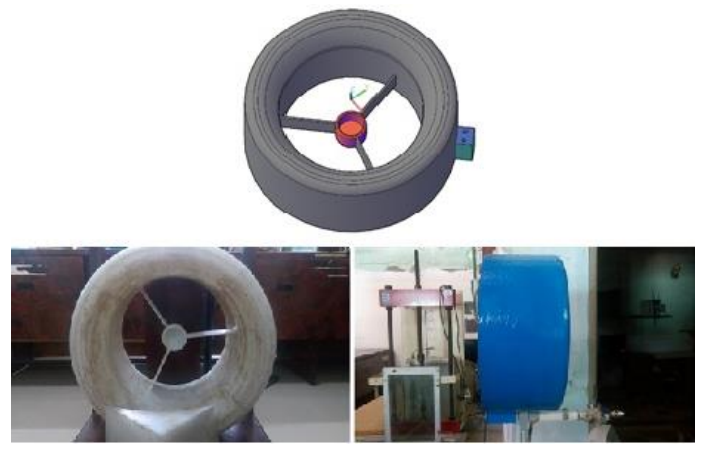

Fig. 9. Duct for experiments

\section{RESULTS}

The proposed thrust measurement system is used for testing of propeller's thrust in static conditions in case of free propeller (non duct) and ducted propeller (see Fig. 9).

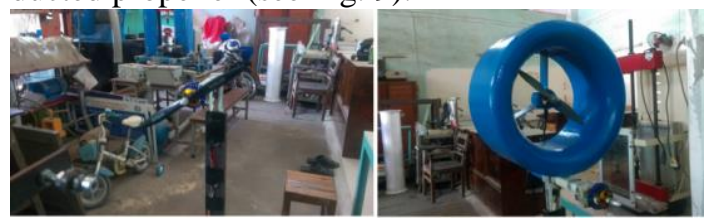

Fig. 10. Propeller's experiments in cases of non duct and with duct

The static thrust of propellers could be expressed by static thrust coefficient $\left(\mathrm{C}_{\mathrm{To}}\right)$. Where:

$$
C_{T_{0}}=T_{0} /\left(\rho n^{2} D_{\text {prop }}^{4}\right)
$$

- $\mathrm{T}_{\mathrm{o}}$ : static thrust

- $\rho$ is air density

- $\mathrm{n}$ : revelutions of propeller per second $(\mathrm{n}=\mathrm{RPM} / 60)$

- $D_{\text {prop}}$ : diameter of propeller.

Tables II, III show the testing results of static thrust of the Master Airscrew E9 $\times 6$ in cases of with duct and non duct. 
TABLE 2

EXPERIMENTAL RESULTS IN CASE WITH DUCT

\begin{tabular}{ccc}
\hline \hline RPM & THRUST (GRAM) & $\mathrm{C}_{\mathrm{T} 0}$ \\
\hline 2509.8 & 80.191 & 0.1343 \\
3553.7 & 166.82 & 0.1394 \\
4182.6 & 238.73 & 0.144 \\
4861.1 & 324.97 & 0.1451 \\
5421.5 & 408.76 & 0.1468 \\
5871.7 & 500.71 & 0.1533 \\
6282.5 & 578.4 & 0.1546 \\
6746.5 & 673.6 & 0.1562 \\
7217.1 & 777.9 & 0.1576 \\
\hline
\end{tabular}

TABLE 3

EXPERIMENTAL RESULTS IN CASE WITHOUT DUCT

\begin{tabular}{ccc}
\hline \hline RPM & THRUST $(\mathrm{G})$ & $\mathrm{C}_{\mathrm{T} 0}$ \\
\hline 2570 & 60.3 & 0.0962 \\
3640 & 122.0 & 0.0976 \\
4030 & 153.0 & 0.0996 \\
4750 & 218.0 & 0.1018 \\
5090 & 246.0 & 0.1001 \\
5330 & 277.0 & 0.1029 \\
5820 & 330.0 & 0.1026 \\
6080 & 365.0 & 0.1043 \\
6620 & 449.0 & 0.1080 \\
\hline
\end{tabular}

The results showed that the ducted propeller has better thrust performance than the non duct propeller, in static conditions (see Fig. 11 and Fig 12).

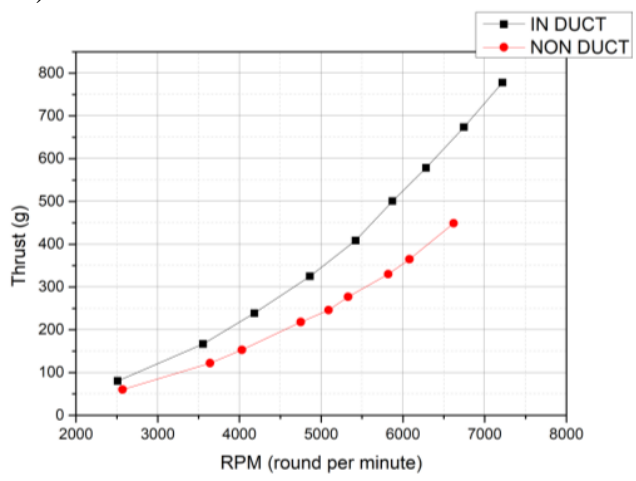

Fig. 11. Comparison of thrust between ducted propeller and non duct propeller

For electric power (calculated by measuring the voltage and electric current to the motor), in the same capacity, the value of the thrust generated by the ducted propeller is larger (see Fig. 13), at low power levels, the differences are not significant, but when the power supply is increased, the difference value increase up.

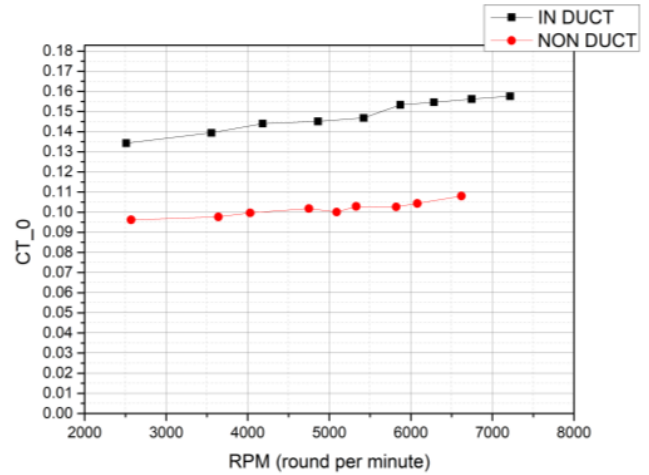

Fig. 12. Comparison of static thrust coefficient between ducted propeller and non duct propeller

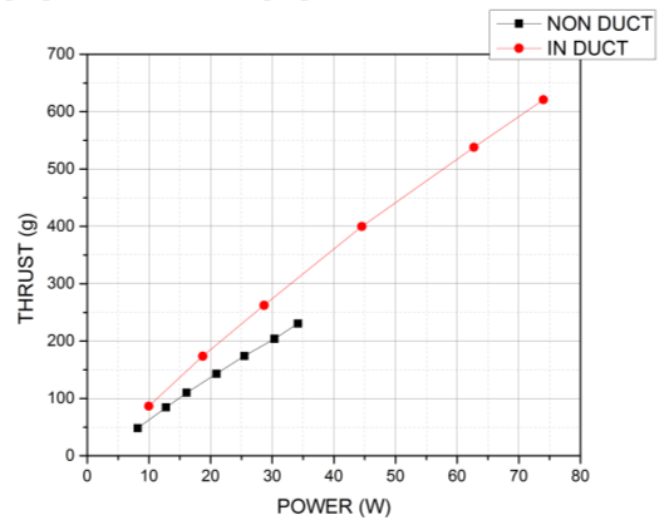

Fig. 13. Thrust versus electric power in cases of ducted propeller and non duct propeller

\section{EVELUATION OF THE RESULTS}

The University of Illinois (USA) had been conducting experiments for the Master Aircrew E9 $\times 6$ propeller in the static conditions. Fig. 14 shows the comparison between the results of the HCMUT and the results of the Illinois University.

So, in case of non duct propeller, at the propeller speed of RPM 6000, the static thrust coefficient captured by HCMUT tests was about 0.105 . In comparison with the static thrust coefficient from the experiments at University of Illinois which is 0.114 , the error is approximately $7 \%$. As described in section 2, the error of the testing system is about $6 \%$, consequently, the error of $7 \%$ comes mainly from the equipment used. So, the proposed thrust measurement system has good methodology and procedure, the obtained results are reliable. And they could be improved with more expensive equipments. 


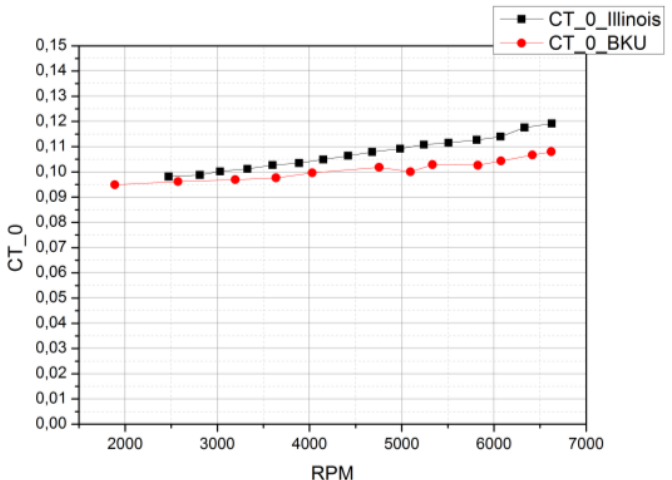

Fig. 14. Static thrust coefficient of MA E9x6 in case of non duct propeller [7]

In case of ducted propeller with duct shape presented in Fig. 8, the tests show that the static thrust coefficients at RPM 5421 is about 0.1468 . The numerical analysis model based on the same duct shape shows that the static thrust coefficient at RPM 5000 is 0.1616 . Therefore, the error of the numerical model is approximately $10 \%$ (see Fig. 15). The results of the simulation, which have been validated by the thrust measurement system with errors below $10 \%$, is acceptable.

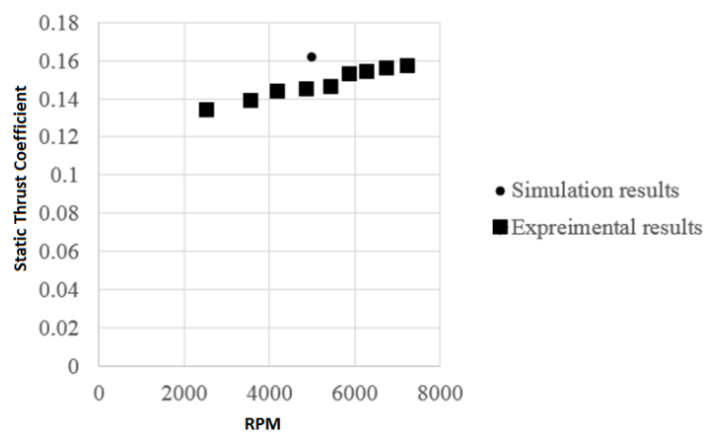

Fig. 15. Use of the thrust measurement system to validate the numerical analysis of MA E9 $\times 6$ with duct [8]

As a result of this validation, the performance characteristics of the MA E9 $\times 6$ with duct, in form of Wageningen 19A standard, could be obtained by the numerical analysis model (see Fig. 16).

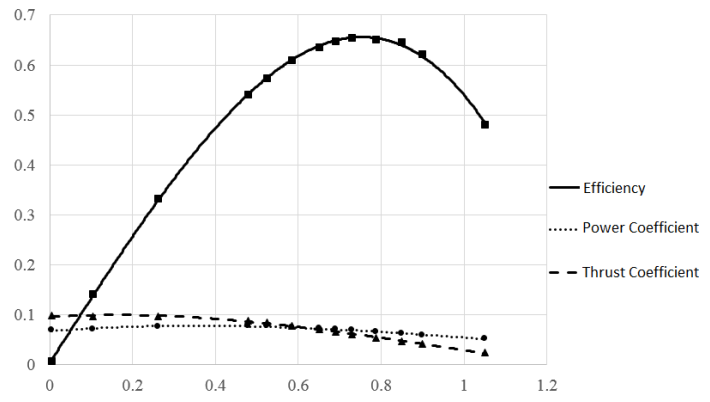

Fig. 16. The characteristics of the MA E9x6 propeller in the duct were constructed by numerical simulation [8]

\section{CONCLUSION}

The thrust measurement system, presented in this paper, is used for the experimental study on the static thrust characteristics of the Master Airscrew E9 66 in cases of with duct and without duct. The results obtained indicate that it could be applied not only to test the thrust characteristics of small UAVS's propellers but also to validate the numerical analysis model for theirs performance. As the results, the thrust testing system could be served as an effective design tool for the selection of small UAVs's propulsion system based on propeller-driven.

In the future, the thrust measurement system should be improved for more realiable and more accurate in order to put on a wind tunnel to study thrust characteristics of ducted propeller.

\section{REFERENCES}

[1]Seong Wook Choi, Yu Shin Kim, Design and Test of Small Scale Ducted-Prop Aerial Vehicle, $47^{\text {th }}$ AIAA Aerospace Sciences Meeting Including The New Horizons Forum and Aerospace Exposition, 5-8 January 2009, Orlando, Florida.

[2]Ngô Khánh Hiếu, Phạm Quốc Hưng, Khảo sát thục nghiệm đặc tính lực đẩy của chong chóng máy bay mô hình, Tạp chí Khoa học Công nghệ Giao thông vận tải, Số 5-6, 2013

[3]Ngo Khanh Hieu, Pham Quoc Hung, Tran Hai Ngoc, Designing a thrust measurement system for thruster of remotely operated underwater vehicle (ROV), Proceedings of National Conference on Mechanics and Transportation Engineering 2017, HCMUT, VNU-HCM, 10/2017.

[4]Virtual Measurement and Control Inc, VLC-A134, www.virtualmc.com

[5]User Manual Javeder JWI 3000, www.weighingmachines.ie/Weighing-Products/Detail/ JWI-3000-Indicator

[6] Marinus Willem Cornelis Oosterveld, Wake adapted ducted propellers, Netherlands Ship Model Basin, 1970.

[7]John B. Brandt, Michael S. Selig, Propeller Performance Data at Low Reynolds Numbers, University of Illinois at Urbana-Champaign, Urbana, 49 $9^{\text {th }}$ AIAA Aerospace Sciences Meeting, USA, 2011.

[8]Nguyen Ngoc Hoang Quan, Ngo Khanh Hieu, Nguyen Thanh Nha, Simulation of the characteristics of the ducted "Master Airscew E9x6" propeller with ANSYS CFX, Proceedings of Vietnam National Conference on Fluid Mechanics, Ha Noi, 2016.

[9]J. D. Van Manen, M. W. C. Oosterveld, Analysis of DuctedPropeller Design, the Annual Meeting, the Society of Naval Architects and Marine Engineers, New York, $11 / 1966$.

[10]Robert J. Weir, Ducted Propeller Design and Analysis, Research report, Sandia National Laboratories, USA, 1987. 
Nguyen Ho Nghia was born in Bien Hoa, Dong Nai, on August 20, 1995. He is currently the $4^{\text {th }}$ year Aerospace Engineering student (the PFIEV propram) at the Ho Chi Minh City University of Technology, Vietnam National University - Ho Chi Minh City.

Ngo Khanh Hieu (1978, Ho Chi Minh, Vietnam) received Bachelor degree in Aerospace Engineering (2001) at Ho Chi Minh City University of Technology, Vietnam National
University - Ho Chi Minh City, M.S. degree in Mechanics (2002) and $\mathrm{PhD}$ degree in Computer Science (2008) from LIAS-ENSMA, France. He is currently an assistant professor of Aerospace Engineering, Ho Chi Minh City University of Technology, Vietnam National University - Ho Chi Minh City. Work experience: Flight Dynamics, Propeller-driven Propulsion System, Control System Analysis and Design.

\title{
Khảo sát thực nghiệm đặc tính của lực đẩy tĩnh của chong chóng Master Airscrew E9x6 trong trường hợp có ống đạo lưu
}

\author{
Nguyễn Hồ Nghĩa và Ngô Khánh Hiếu
}

\begin{abstract}
Tóm tắt—Các nghiên cứu trước đây ở Đại học Bách Khoa hầu hết đều thực hiện với trường hợp chong chóng tự do, không có dữ liệu cho trường hợp chong chóng nằm trong ống đạo lưu. Về mặt lý thuyết chong chóng trong ống đạo lưu có một số đặc tính tốt hơn so với trường hợp tự do. Bài báo trình bày thiết kế thí nghiệm cho chong chóng cỡ nhỏ. Mô hình thí nghiệm sẽ được thực hiện đối với chong chóng AirScew E9x6 trong trường hợp có ống đạo lưu và không có ống đạo lưu, ở điều kiện tĩnh. Các kết quả thu được sẽ được so sánh với kết quả của nhà sản xuất (tiến hành bởi Đại học Illinois, trường hợp không có ống đạo lưu, trong điều kiện tĩnh), và so với các kết quả mô phỏng số (trường hợp có ống đạo lưu). Từ đó đưa ra kết luận cho việc lựa chọn loại chong chóng phù hợp với mục đích sử dụng của loại UAV.
\end{abstract}

Tù $\boldsymbol{k} \boldsymbol{h}$ óa — chong chóng trong ống đạo lưu, chong chóng Master Airscrew E9x6 